\title{
Liberalisation, consumption heterogeneity and the dynamics of energy prices
}

\author{
Paula Ferreira ${ }^{1}$ \\ Department of Production and Systems, University of Minho \\ Azurém \\ 4800-058 Guimarães \\ Portugal \\ Tel: +351253510340 \\ Fax: +351253510343 \\ Email: paulaf@dps.uminho.pt \\ Isabel Soares \\ Faculty of Economics of Porto, University of Porto \\ Rua Dr. Roberto Frias \\ 4200-464 Porto \\ Portugal \\ Tel: +351225571100 \\ Fax: +351225505050 \\ Email: isoares@fep.up.pt \\ Madalena Araújo \\ Department of Production and Systems, University of Minho \\ Azurém \\ 4800-058 Guimarães \\ Portugal \\ Tel: +351253510340 \\ Fax: +351253510343 \\ Email: mmaraujo@dps.uminho.pt
}

In this study, the methodology VAR and the cointegration analysis are used to examine the dynamic interaction among the energy prices of the competitor energy sources in a liberalised market. Data from the UK market were applied, and models for the residential and industrial sectors were developed. Our results indicate the existence of long-run relationships between the energy prices before and after the liberalisation, implying the possibility of substitution among the different forms of energy. However, the results appear to be also largely influenced by external variables not included in the models that may be reducing the importance of the energy prices over their own evolution and offsetting the basic substitution relationships. The general results of the Impulse Response Functions, both for the residential and industrial sectors, present low statistical significance, which seems to be due to the still slow rate of adjustment of the energy market to price changes, along with the immaturity of the liberalisation process. Taking into consideration the results, some routes for future research are pointed out, namely the need to include in the analysis variables which would proxy the general state of the economy.

The authors gratefully acknowledge an anonymous referee for helpful comments.

KEYWORDS: Energy prices, liberalisation, VAR model

\section{INTRODUCTION}

In the past 20 years considerable changes have been occurring on the energy markets. The traditional public management is being gradually replaced by private management, and the traditional utility monopolies tend to be dismantled, giving place to free and competitive markets.

In the European Union (EU), important steps have been taken to meet liberalisation objectives in the energy market. The electricity directive 96/92/EC and the gas directive 98/30/CE were adopted, laying down the rules to allow for real competition and to give the consumers a free choice of energy suppliers. 
The competition in the EU countries is being gradually introduced, with countries adopting the system best suited to their particular circumstances, as it is foreseen in the Directives. In October 2002, the Commission of the European Communities reported that the electricity market was around 70\% open to competition in the EU and would rise to $85 \%$ by 2005 . Only four members do not intend to fully open their electricity markets. For natural gas, the equivalent figures are 80\% now, rising to 90\% by 2005 .

The development of competition in the EU energy market, is expected to lead to a rising number of competitors in the market, and consequently more contractual flexibility, improving all the market dynamics, reducing prices and improving the quality of the services.

However, it is also important to notice that beyond the competition between suppliers of the same energy type there is also competition between different forms of energy. For example the fuel oil burning in industry can be replaced by the natural gas or coal burning and vice-versa. This way, the liberalisation of each energy sub sector has a strong influence on all the others competing in the market. At the same time, the liberalisation of the energy markets will lead to the development of new supply companies, trading and supplying different energy types with strategies that will also largely influence the market reactions.

The Commission of the European Communities (2001) believes that the introduction of competition on the energy markets will put downward pressure on the deliver prices, due to the larger number of suppliers competing for the same market. Also, the OECD Economic Outlook (OECD, 2000), pointed out that the empirical evidence on the effects of liberalisation, suggests that prices tend to decline after this market reform. However, the energy markets are also strongly influenced by other factors, specially the international oil prices, increasing the difficult in separating the liberalisation impact on prices from other external factors. In the EU for example there has been a clear reduction of the electricity prices after the implementation of the electricity directive. However, the results of liberalisation on the natural gas prices are not as clear, due to its strong link to the oil prices.

The question of the inter fuel relationship has already been brought to light by several authors, especially in what concerns the interfuel substitution possibilities, with the aim of analysing the likely effects of some policy changes (for example new taxes) on the energy consumption structure. The subject is still controversial, not only regarding the substitution possibility among the different forms of energy, but also in the market rate of adjustment. There are some studies focusing on the residential sector (see for example Garcia-Cerrutti, 2000, Ryan et al, 1996 or Haas and Schipper, 1998), but a large part of these empirical studies were dedicated to the industrial sector, like Pindyck (1979), Jones (1995 and 1996), Renou-Maissant (1999), among many others ${ }^{2}$.

The current paper aims to contribute to the discussion of the energy price analysis, exploring the market dynamics and the price responsiveness of the new liberalised energy markets. As Pindyck and Rotemberg (1983) pointed out, for policy decision analysis it is extremely important to analyse the pattern of energy demand responses over time, which require the use of dynamic models. This work focus on the dynamic interaction among the energy prices of the different energy sources in a liberalised market. The aim is to study the price responses, when variations occur in the competitors energy sources prices, using the method of vector auto regression (VAR) developed by Sims (1980). Our objective is to check the existence of relationships between the variables considered, using the VAR and cointegration analysis, in order to assess the impacts of fuel price variations.

The decision to focus this study in the UK market was basically due to its full effective market opening. It developed already new flexible mechanisms for trading energy and its gas and electricity sectors are completely liberalised. As a matter of fact it is worth noticing that price trends are frequently distorted by regulatory rebalancing of distribution tariffs in countries where the liberalisation is still underway. It is the case of Italy and Ireland in recent years for electricity, while in UK, Germany and Austria prices have fallen across all consumers. Also in Sweden and Finland prices are either falling or stable at low levels. For gas, the situation differs quite a lot among member states. In France, Spain and Sweden for example, price reductions for large users have often been offset by high (or increasing) prices for households and small business (Commission of the European Communities, 2002). Effectively the UK remains a credible sample of a full, effective market opening without the specific, peculiar features of the Nordic energy market.

The structure of the paper is as follows. Section 2 describes briefly the energy environment in UK. Section 3 presents the methodology and the data used in the research here reported. Section 4 presents 
the empirical results. In section 5 a discussion of the results is done. The main conclusions are summarized in section 6 .

\section{THE UK ENERGY MARKET}

The energy market in the UK has been immersed in deep changes for the last two decades. The liberalisation began in the late 80's and the full opening of the market was achieved in 1999, when all the electricity consumers were eligible to choose their supplier. This way, UK was a pioneer in these energy reforms and its experiences extremely influenced the reform processes all across the world, including the $\mathrm{EU}^{3}$.

Competition in natural gas and electricity supply has been introduced in stages as it is shown in Table 1 (Department of Trade and Industry, 2003a).

Table 1-Phases of competition in natural gas and electricity supply markets in EW

\begin{tabular}{llll}
\hline \multicolumn{1}{c}{ Natural gas market } & \multicolumn{1}{c}{ Electricity market } \\
\hline End 1986 & $\begin{array}{l}\text { Three quarters of non-residential 1990 } \\
\text { market was effectively opened to } \\
\text { competition, by the inclusion of } \\
\text { customers with demand above 25000 } \\
\text { therms per year. }\end{array}$ & $\begin{array}{l}\text { About 30\% of the market was open to } \\
\text { competition, by the inclusion of } \\
\text { customers with maximum demand over } \\
1 \mathrm{MW}\end{array}$ \\
\hline $\mathbf{1 9 9 2}$ & $\begin{array}{l}\text { The market was opened for practically 1994 } \\
\text { all the non-residential consumers, by } \\
\text { the inclusion of customers with } \\
\text { demand between 2500 therms and } \\
\text { 25000 therms per year. }\end{array}$ & $\begin{array}{l}\text { Next 15\% of the market was open to } \\
\text { competition, by the inclusion of } \\
\text { customers with maximum demand } \\
\text { between 100 kW and } 1 \text { MW. }\end{array}$ \\
\hline $\mathbf{1 9 9 6 - 1 9 9 8}$ & $\begin{array}{l}\text { The remaining market was } \mathbf{1 9 9 8 - 1 9 9 9} \\
\text { progressively opened given the freedom } \\
\text { to choose their supplier for all the } \\
\text { customers. }\end{array}$ & $\begin{array}{l}\text { The remaining 55\% of the market was } \\
\text { progressively opened, covering all the } \\
\text { electricity market. }\end{array}$ \\
\hline
\end{tabular}

The International Energy Agency (2002), recognises that since the liberalisation both markets have become highly competitive, with high rates of supplier switching and considerable reduction of consumers bills. In fact, the UK presents average electricity and natural gas prices substantially lower than the EU average, especially for the gas supply to household sector where the UK reforms are much ahead of most of the other EU members.

Between 1995 and 2002, average annual residential electricity prices, including VAT, fell by 27\% in real terms, while for the industrial consumers, prices fell about 38\% over the same period. Compared to 1990, the year of the beginning of the electricity reforms, average electricity prices in 2002 were $42 \%$ lower for the industrial sector and $26 \%$ lower in the residential sector ${ }^{4}$.

The average residential gas prices were by 2002, about 15\% lower in real terms than in 1995 and $31 \%$ than in 1986, the year of the beginning of gas reforms in the UK. As for the industry sector, the average natural gas prices fell 51\% between 1986 and 2002. However, since 2000 these prices have been increasing, driven up by the increase in the spot price of gas largely due to the link of natural gas price to oil in continental Europe.

The evolution of the electricity and natural gas prices is closely related with the reform scheduling. In fact, between 1994 and 2002 the smallest electricity users present the larger fall for the real electricity prices among all group of the industrial consumers, reflecting the fact that consumers with the maximum demand over $100 \mathrm{~kW}$ had access to the free market after 1994. Also, despite the 33\% real price increase of gas for the industrial sector over the period 1996-2002, real prices for residential gas consumers fell by $13 \%$, largely due to the development of supply competition for the small gas consumers after 1996.

Through the last two decades the reforms of the UK energy industry have led to considerable changes, not only in the energy prices evolution, but also in the energy demand structure of all sectors. The most 
remarkable change was the movement away from coal and the increasing of the natural gas consumption share across all sectors. In 2002, coal held a 2\% overall consumption share down from 9\% in 1990, whereas natural gas share increased from 31\% to 36\%. This movement was especially evident in the electricity generation sector, where the share of natural gas has grown from $1 \%$ to $32 \%$ and the coal share has fall from 65\% to 38\% between 1990 and 2002, mostly due to the entry of independent power producers operating combined cycle gas turbines plants and to the disinvestments on coal plants ${ }^{5}$.

In 2002, the transport sector represented the biggest energy user, accounting for 35\% of final energy use. Residential sector accounted for 30\%, industry for 22\% and other sectors for $13 \%$. Between 1990 and 2002, the final consumption of the industrial sector has declined about $10 \%$. On the other hand, the residential energy consumption presented the biggest growth among all sectors, increasing by $17 \%$ during this period. In 2002, natural gas held the biggest energy consumption share both in the industrial and residential sectors (44\% and 68\% respectively) , followed by electricity (28\% and 21\%), oil (19\% and $8 \%)$ and finally coal (5\% and $3 \%)^{6}$.

\section{METHODOLOGY AND DATA}

In order to analyse the relations between the prices of different forms of energy a VAR is utilized. The VAR model consists of a system of equations, where every endogenous variable is treated as a function of the lagged variables of all the endogenous variables in the system. This methodology is frequently used in the production of forecasts and for analysing the dynamic impact of different types of random disturbances on systems of variables. The mathematical representation of VAR is given by:

$$
Y_{t}=\beta_{0}+\beta_{1} Y_{t-1}+\beta_{2} Y_{t-2}+\ldots . .+\beta_{p} Y_{t-p}+U_{t}
$$

where:

$Y_{t}$ is the vector of the endogenous variables $(k \times 1)$,

$\beta_{0}$ is the vector of constants to be estimated $(\mathrm{k} \times 1)$,

$\beta_{1}, \ldots, \beta_{\mathrm{p}}$ are the matrices of the coefficients to be estimated ( $\left.\mathrm{k} \times \mathrm{k}\right)$,

$\mathrm{U}_{\mathrm{t}}$ is the vector of the error terms $(\mathrm{k} \times 1)$ and

$\mathrm{p}$ is the lag.

The empirical analysis of this paper is carried out using time series of the main energy types prices consumed in residential and industrial UK sectors. Considering the scheduling of the liberalisation process it was decided to present two models for the residential sector. The first model covers the period before the beginning of the electricity liberalisation, from January 1990 to August 1998. The second model covers the period after liberalisation, from September 1998 to September 2002. The empirical analysis in the residential sector employs monthly data on the retail price indices of coal (co), electricity (e), natural gas (g) and heating oils (o).

For the industrial sector only one model was estimated for the period after liberalisation, since these consumers had access to free electricity and natural gas since 1990, at least the largest ones. The empirical analysis in the industrial sector employs quarterly data of the average prices indices of coal (co), electricity (e), natural gas (g) and fuel oil (o), over the period of 1990:01 to 2002:2.

The models were estimated using real prices seasonally adjusted and logarithmic transformed. All data were drawn from the Department of Trade and Industry (2002) ${ }^{7}$.

The first question to be addressed is the stationarity of the data series in order to decide if the model should be specified in levels or in a differentiated form. In this paper both the Augmented Dickey-Fuller and the Philips-Perron tests are applied (Dickey and Fuller, 1979 and 1981 and Philips-Perron, 1988) to test the presence of unit roots in the time-series data, which implies non-stationarity. In order to confirm these results the correlograms of the data series were also analysed, both in levels and after differentiation.

Engle and Granger (1987) showed that if the set of variables is cointegrated, estimating a VAR model using first differences might result in serious loss of information about the long run equilibrium relationship among the variables. These cointegration relationships will also be included in the analysis, forming the basis of the VEC (Vector Error Correction Model) specification. This model is a restricted VAR, which has the ability to incorporate short-term dynamic elements, with long-run equilibrium 
relationships among variables (cointegration relations). To check the existence of these cointegration relationships, the Johansen trace test will be used (Johansen, 1991).

Authors like Sims (1980) and Chang et al (2001), pointed out that the estimated coefficients of a VAR model are not easy to describe and interpret. In order to draw conclusions about the linear dynamics of the variables, the impulse response function (IRF) generated from the VAR models will be analysed. The IRF traces the effect that a one-standard-deviation-shock to one of the endogenous variables has on current and future values of all variables in the system. It enables the characterisation of the dynamic interactions among the variables, and the observation of the variables adjustment speed (Chang et al., 2001 and Bussel, 1997). For example, the IRF's show the expected responses of natural gas price to a change in oil price, allowing to know if the response is permanent or transitory, positive or negative and its duration.

As the results of the IRF are sensitive to the ordering of the variables in the VAR, this ordering was decided by empirical considerations: being electricity a secondary energy form, it will be placed in last. In spite of the UK being a natural gas and oil producer with autonomous markets, UK prices may also be contaminated by the fact that natural gas price in Europe is still linked to the oil price. It was then decided to place natural gas after the oil price. Finally, as there is no clear linkage between coal price and oil or natural gas prices, the coal will be placed in first. Also, the reduction of the UK coal production and the growth of its imports, makes this fuel increasingly dependent on the variations of the international prices. Based on this empirical approach, it was decided to order the variables in the following way ${ }^{8}$ :

$\mathrm{co} \Rightarrow \mathrm{O} \Rightarrow \mathrm{g} \Rightarrow \mathrm{e}$

\section{EMPIRICAL RESULTS}

\subsection{Unit root tests}

The variables were tested for non-stationarity using the ADF and PP tests. The results of these tests are shown in Table 2, both in levels and after one differentiation (prefixed by $\Delta$ ).

Table 2- ADF and PP tests for stationarity

\begin{tabular}{ccccccc}
\hline & \multicolumn{2}{c}{ Residential sector (1990-1998) } & \multicolumn{2}{c}{ Residential sector (1998-2002) } & \multicolumn{2}{c}{ Industrial sector } \\
Variables & $\mathrm{ADF}^{\mathrm{a}}$ & $\mathrm{PP}$ & $\mathrm{ADF}^{\mathrm{a}}$ & $\mathrm{PP}$ & $\mathrm{ADF}^{\mathrm{a}}$ & $\mathrm{PP}$ \\
\hline $\mathrm{co}$ & $-1,948$ & $-2,442$ & $-0,822$ & $-0,754$ & $-2,473$ & $-2,142$ \\
$\mathrm{~g}$ & $-0,589$ & 0,017 & $-1,927$ & $-1,951$ & $-1,835$ & $-1,504$ \\
$\mathrm{E}$ & 1,010 & 0,798 & $-0,640$ & $-0,639$ & 2,261 & 1,840 \\
$\mathrm{o}$ & $-1,447$ & $-2,433$ & $-1,619$ & $-1,618$ & $-1,251$ & $-1,635$ \\
$\Delta \mathrm{co}$ & $-13,066^{*}$ & $-13,152^{*}$ & $-7,909^{*}$ & $-7,883^{*}$ & $-11,324^{*}$ & $-10,978^{*}$ \\
$\Delta \mathrm{g}$ & $-4,755^{*}$ & $-9,872^{*}$ & $-6,571^{*}$ & $-6,575^{*}$ & $-3,229^{* *}$ & $-3,306^{* *}$ \\
$\Delta \mathrm{e}$ & $-4,630^{*}$ & $-8,774^{*}$ & $-6,834^{*}$ & $-6,834^{*}$ & $-4,735^{*}$ & $-4,759^{*}$ \\
$\Delta \mathrm{o}$ & $-2,107$ & $-9,133^{*}$ & $-6,118^{*}$ & $-6,118^{*}$ & $-3,785^{*}$ & $-6,313^{*}$ \\
\hline
\end{tabular}

${ }^{a}$ The lag order of the augmented term was chosen by the Akaike Information Criterion (AIC).

* Denotes significance at the $1 \%$ level. ** Denotes significance at the $5 \%$ level.

The results do not establish stationarity for the levels of any of the series, so the null hypothesis of a unit root is accepted for the level series. In contrast, and according to PP tests, the non stationarity of the differentiated series can be rejected for all the data series at least at the 5\% significance level. Based on the ADF tests non stationarity could not be rejected for the differentiated heating oils prices for the residential sector (1990-1998) ${ }^{9}$. However, its graph and correlogram did not present an evident nonstationary pattern. For all the others differentiated series, the ADF tests suggest stationarity at least at the $5 \%$ significance level. According to these results, it was assumed that all the time series are stationary after one differentiation.

\subsection{Cointegration tests}

Based on the evidence for the presence of an unit root in all the data series, the next stage will be to test the possibility of cointegration among the variables. A VAR model was fitted to the data, using the AIC criterion as a first approach to derive the optimal lag length. Next, diagnostics tests were performed on the residuals of each equation and the lag length was adjusted in order to assure the statistical validity of the model and the simultaneous maximisation of the degrees of freedom. 
The test results suggest $\mathrm{p}=9$ for the residential sector (1990-1998), $\mathrm{p}=3$ for the residential sector (19982002) and $p=2$ for the industrial sector ${ }^{9}$. Table 3 reports the results of the Johansen cointegration tests, considering that the data series have no deterministic trends and the cointegration equations have intercepts.

Table 3- Johansen cointegration tests

\begin{tabular}{|c|c|c|c|c|c|c|}
\hline \multirow{2}{*}{$\begin{array}{c}\text { Hypothesized number } \\
\text { of cointegration } \\
\text { equations }\end{array}$} & \multicolumn{2}{|c|}{$\begin{array}{c}\text { Residential sector } \\
(1990-1998)\end{array}$} & \multicolumn{2}{|c|}{$\begin{array}{c}\text { Residential sector } \\
(1998-2002)\end{array}$} & \multicolumn{2}{|c|}{ Industrial sector } \\
\hline & $\begin{array}{c}\text { Trace } \\
\text { statistic }\end{array}$ & $\begin{array}{l}5 \% \text { critical } \\
\text { value }\end{array}$ & $\begin{array}{l}\text { Trace } \\
\text { statistic }\end{array}$ & $\begin{array}{l}5 \% \text { critical } \\
\text { value }\end{array}$ & $\begin{array}{l}\text { Trace } \\
\text { statistic }\end{array}$ & $\begin{array}{l}5 \% \text { critical } \\
\text { value }\end{array}$ \\
\hline None & $85,50 *$ & 53,12 & $71,39 *$ & 53,12 & $68,75^{*}$ & 53,12 \\
\hline At most 1 & 31,19 & 34,91 & $39,56 *$ & 34,91 & 28,92 & 34,91 \\
\hline At most 2 & 14,53 & 19,96 & 19,88 & 19,96 & 12,06 & 19,96 \\
\hline At most 3 & 5,41 & 9,24 & 3,99 & 9,24 & 3,46 & 9,24 \\
\hline
\end{tabular}

* Denotes rejection of the null hypothesis at the $5 \%$ significance level.

The results suggest the existence of one cointegration relationship between the four variables both for the residential (1990-1998) and industrial sectors, at the 5\% significance level. For the residential sector (1998-2002), the test statistics indicate the presence of two cointegration equations at the $5 \%$ significance level.

The resulting normalized parameters estimates are:

Residential sector (1990-1998)

Residential sector (1998-2002)

$$
\begin{aligned}
& \mathrm{co}=0.474 \mathrm{~g}-0.068 \mathrm{e}-0.174 \mathrm{o}+3.534 \\
&(-6.270)^{*}(1.280)(7.242)^{*}(-15.548) *
\end{aligned}
$$

$$
\begin{aligned}
\text { co }= & -0.821 \mathrm{e}-0.172 \mathrm{o}+8.851 \\
& (3.582)^{*}(3.520)^{*}(-7.693) * \\
\mathrm{~g}= & -0.215 \mathrm{e}-0.1560+6.001 \\
& (2.533)^{*}(8.620)^{*}(-14.080)^{*}
\end{aligned}
$$

Industry sector

$$
\begin{aligned}
\mathrm{Co}= & -0.421 \mathrm{~g}+2.441 \mathrm{e}+1.826 \mathrm{o}+12.635 \\
& (1.899)^{* *}(-5.926)^{*}(-5.147)^{*}(4.707)^{*}
\end{aligned}
$$

where the numbers in brackets are the t-statistics (* statistical significance at the $95 \%$ level, ** statistical significance at the $90 \%$ level).

Equation (2) reflects a positive significant long run relationship between the coal and the natural gas prices, as well as a positive relationship between heating oil and gas prices, implying the possibility of substitution between these fuels. The negative relationship between the coal and heating oils prices is more difficult to explain since it may result from an apparent complementarity. For the residential sector after liberalisation negative inter-fuel relationships were also detected. In fact, Equation (3) implies a negative relationship between the coal, electricity and heating oils prices. The same way, equation (4) represents a long run negative relationship between natural gas, electricity and heating oils prices. These somewhat questionable results also occurred in some other studies, like Pindyck (1979), Lin et al (1987), or more recently Garcia-Cerruti (2000) who detected negative cross-price elasticities between some energy types.

The negative cross-price effects presented in the residential sector equations may be ascribed to several external factors, tending to offset the basic substitution relationships. One possible explanation for the negative inter-fuel relationships, pointed out by Garcia-Cerruti (2000), is based on the assumption that "....increases in energy prices make income share devote to energy costs larger and provide a strong incentive to use all appliances less intensively...". For example, an increase in the coal prices leads to a reduction not only of its demand but also of the heating oil demand, resulting in a reduction of the heating oil price. 
Additionally, Fouquet et al (1997) detected some evidences in the UK that an increase in income can lead eventually to the substitution of less efficient fuels by more efficient ones. Haas and Schipper (1998) defend also that the income growth stimulates equipment turnover to more efficient one. This way, an increase in income may lead to the substitution of heating oils by natural gas, resulting in the reduction of the heating oil demand, followed by a reduction of its price, and in the increase of the natural gas demand, and consequently increasing its price.

The important rule of the income is also assumed in the work of Lin et al (1987), who detected negative responses of electricity and natural gas to heating oil price increases for the residential sector. According to this study, an increase in heating oil prices accompanies increases in all other petroleum products, which will represent a reduction in real income, resulting in a negative effect on the other energy types.

From equation (5) we have a positive long run relationship between coal and electricity and between natural gas and electricity that we think is also mostly due to the coal and natural gas usage for electricity generation. An increase in coal or natural gas price will lead to an increase of the electricity production cost and consequently increasing the price charged to the consumers, resulting in these positive relationships. This effect seems to be more important than the income consequences. As for the negative relationship between electricity and fuel oil prices, the income effect may be once more responsible for this apparent complementarity, as it was referred before for the residential sector.

Equation (5) also presents a positive long run relationship between the coal and the fuel oil prices, as well as a positive relationship between fuel oil and gas prices, implying the possibility of substitution between these fuels. The negative relationship between the coal and gas prices may be once more associated with the income effect.

\subsection{Impulse response function}

The use of the IRF allows the observation of the dynamic behaviour of each variable due to a one standard deviation random shock given to one of the other variables in the system. During our analysis it was verified that the IRF pattern of the VAR and VEC models, are quite similar in the short run but show some divergence in the longer run, which is consistent with Naka and Tufte (1997) who concluded that the VEC model and the VAR in levels yield reasonably similar IRF at short horizons, but different at long horizons. Following the procedure adopted by other authors (see for example Chang et al, 2001 or Anari et al, 2002), only the IRF's obtained with the unrestricted VAR are reported.

Figure 1 plots the IRF for the VAR model estimated for the residential sector for the period 1990-1998 by the order $\mathrm{co} \Rightarrow \mathrm{a} \Rightarrow \mathrm{g} \Rightarrow \mathrm{e}$. The size of the shock was set to one standard deviation of the residuals. The dotted lines represent a two standard deviation confidence band.

The response of coal price is significantly affected by its own shocks during two months and by the natural gas price shocks during three months; after that it tends to zero. All the other variables do not seem to affect the coal price in a significant way, once its values remain close to the initial ones and are statistically nulls. Similarly, the heating oils price responds significantly only to its own shocks, during the first six months. After that, it tends to restore its initial values. The price shocks on other variables show no statistical significant effect on heating oils price. The natural gas price is only significantly affected by its own shocks during the first three months, becoming practically null after this period. The coal and heating oils prices shocks effect on natural gas price tends to be near zero, but the electricity price shocks lead to a rise on natural gas prices after the eighth month, although remaining always statistically non significant. The response of electricity to its own shocks, shows a persistent effect and do not present any die out pattern, but it is only statistically significant for the first five months. The remaining price shocks do not affect significantly the electricity prices.

This way, the results indicate that all the variables respond mostly to their own shocks, for the residential sector for the period before liberalisation. The model did not capture any clear relation between the different energy types, seeming that their prices are independent of each other. This may result from the low price sensitiveness of the residential energy consumption, ensuring a relatively stable demand for the monopolist suppliers. This way, in the short run the demand of each energy type is not significantly affected by the fluctuation of the others prices, and consequently its price remain also nearly unaffected. 

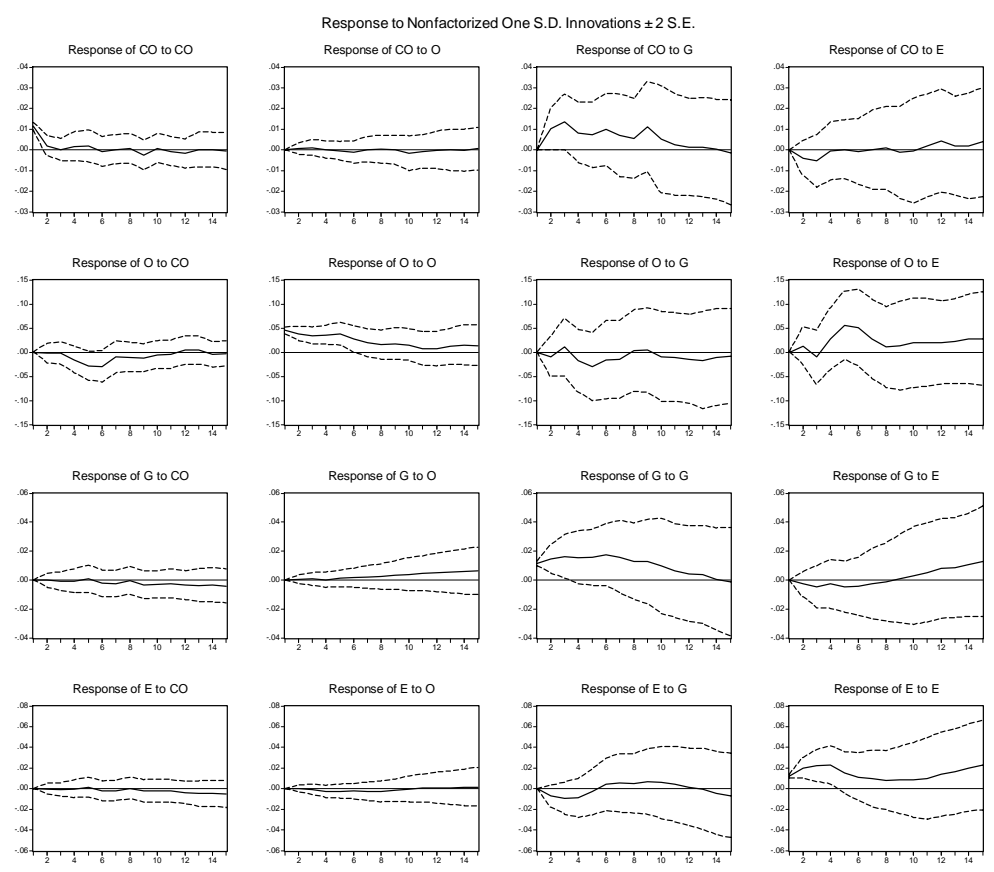

Figure 1- Impulse response functions for the residential sector (1990-1998). Ordering: $c 0 \Rightarrow 0 \Rightarrow g \Rightarrow e$. 
Figure 2 plots the IRF for the residential sector for the period $1998-2002$ by the order $c 0 \Rightarrow 0 \Rightarrow g \Rightarrow e$. The results by the reverse order are not significantly different. The size of the shock was set to one standard deviation of the residuals. The dotted lines represent a two standard deviation confidence band.
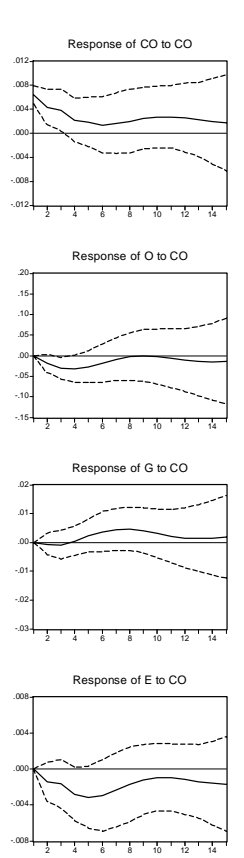
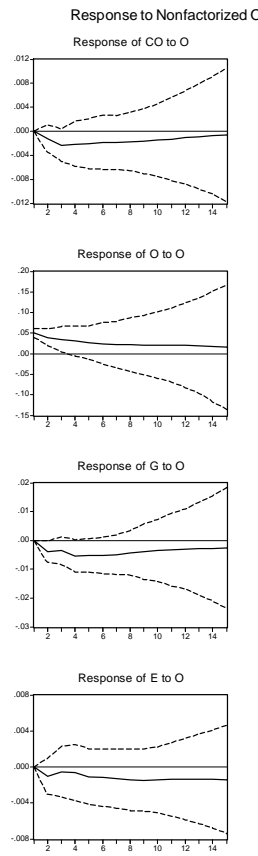
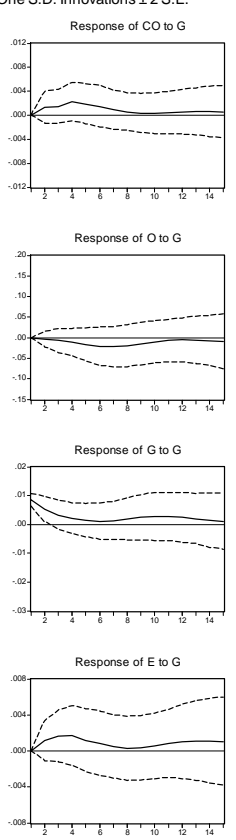
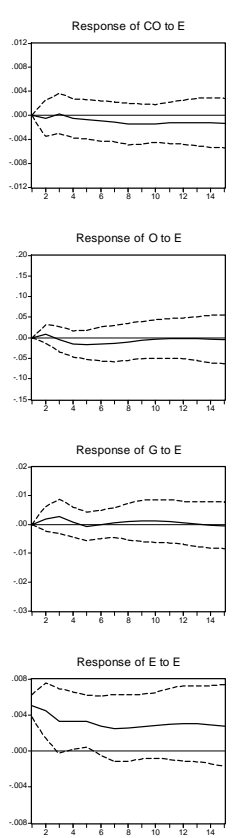

Figure 2- Impulse response functions for the residential sector (1998-2002). Ordering: $c 0 \Rightarrow 0 \Rightarrow g \Rightarrow e$.

The coal price is only significantly affected by its own shocks, during four periods. After that, this effect shows a die out pattern. The effect of the natural gas and electricity prices shocks on coal price tend to be near zero, but the heating oils price shocks lead to negative effect on coal prices, although remaining always statistically non significant. The heating oils price reveals a negative immediate response to coal price shocks statistically significant between the third and the fifth months. It shows a small negative response to the gas price shocks during the entire forecast horizon. The response weakens after the eleventh month and shows no statistical significance during the entire forecast period. The heating oils price is also affected by its own prices and shows a slow die out pattern, but it is only statistical significant untill the fourth month. The natural gas price responds significantly to its own shocks only for three months. After that, it tends to values close to the initial ones. The response of natural gas price to a shock in the heating oils price, shows statistical significance during the first three months, and maintains a persistent negative effect. The coal price shocks effect on gas prices tend to be initially negative but becomes positive after the fifth month, although remaining not significantly different from zero during all the period. The responses of the electricity price to its own shocks show statistical significance for three months and have no die out pattern. The heating oils and natural gas price shocks do not affect significantly the electricity price once its values remain close to the initial ones. Also, the electricity response to coal price shocks, although remaining negative during the entire forecast horizon, has no statistical significance.

Although detecting a few significant responses, the general results of the IRF after liberalisation maintain a low statistical significance. The model did not capture significant changes in the market in what concerns relationships between the prices of the different energy types in the short run. The low significance of the results may be associated with the still reduced and slow responsiveness of the consumers, due to the immaturity of the market. The recent reforms implied also the use of a reduced amount of data (1998-2002 timeframe) which also seriously jeopardise the model significance.

Figure 3 plots the IRF for the industrial sector by the order $\mathrm{c} 0 \Rightarrow 0 \Rightarrow \mathrm{g} \Rightarrow \mathrm{e}$. The results by the reverse order are not significantly different. The size of the shock was set to one standard deviation of the residuals. The dotted lines represent a two standard deviation confidence band. 

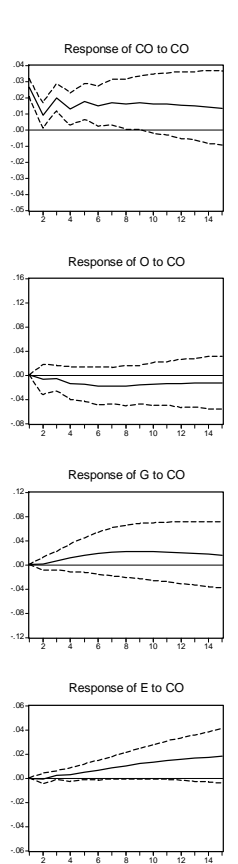
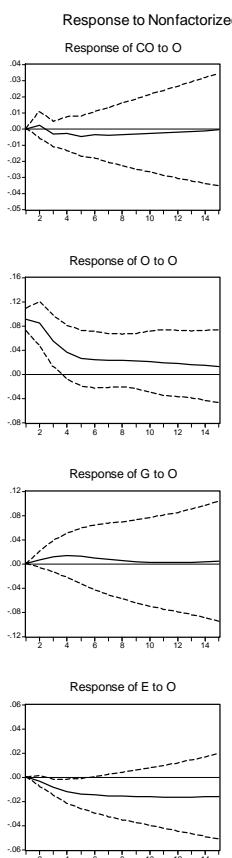

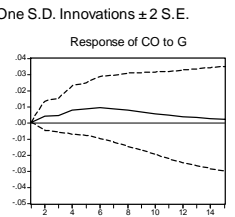

Response of $\mathrm{O}$ to $\mathrm{G}$
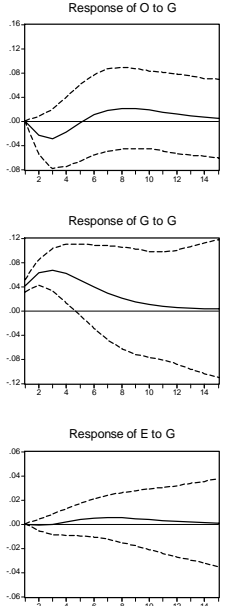

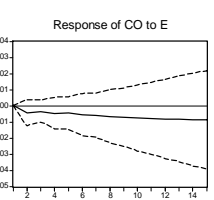

Response of $\mathrm{O}$ to $\mathrm{E}$

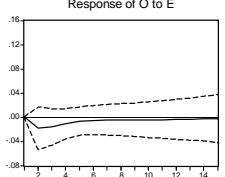

Response of $\mathrm{G}$ to $\mathrm{E}$
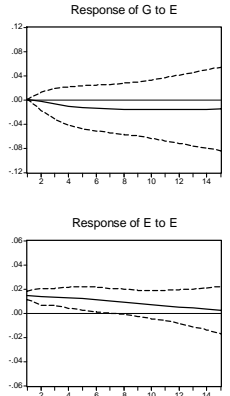

Figure 3- Impulse response functions for the industrial sector. Ordering: $c o \Rightarrow 0 \Rightarrow g \Rightarrow e$.

The coal price only responds significantly to its own shocks. The response peaks at the fist quarter, declines until the second quarter, and then rebounds after that period. It shows statistical significance until the eleventh quarter. The shocks in fuel oil and electricity price have no significant impact on coal price, which shows a near zero response. The natural gas price shocks lead to a positive effect that gradually becomes practically null and it is statistically non significant during the entire forecast horizon. The fuel oil price responds significantly to its own shocks during four quarters. The response weakens after that and becomes close to zero. The coal and electricity prices shocks have small negative non-significant effect on fuel oil prices, which remain close to their initial values. The gas price shocks effect on fuel oil price tends to be initially negative but become positive after the fifth quarter, although not significantly different from zero during all the period. The response of the natural gas price to its own shocks shows statistical significance during five periods, and after that it gradually returns to its initial values. The shocks on the other variables do not seem to affect significantly the natural gas prices. The electricity price responds significantly to its own price shocks during the first eight trimesters. It also responds positively to the coal price shocks, maintaining statistical significance after the ninth quarter and showing no die out pattern. The fuel oil prices shocks lead to a persistent negative response on the electricity price, statistically significant between the third and seventh trimester. The natural gas prices shocks do not affect significantly the electricity prices once their values remain close to the initial ones (with some small flotation moves).

The general results of the IRF for the industrial sector present also low statistical significance. The small magnitude of these responses may result from the slow rate of adjustment of the market, due for example to technological constraints. Also, during the period considered for the model estimation several contributing facts are worth while noticing: not all the industrial consumers had access to the free market; several changes were still taking place in the market; and the data used do not represent a complete liberalised market. In fact, the market was only fully opened by 1998 to 1999. The natural gas use for power generation was just starting and smaller industries had yet no access to the free energy market. As for the electricity market, only about $45 \%$ of the market was opened for competition in 1994 . This means that the data used contained a mixture of liberalised and non-liberalised prices. This fact, along with the heterogeneity of the industrial sector, clearly contributes to complicate the task of estimating a general significant model.

\section{DISCUSSION OF THE RESULTS}

In the residential sector before the liberalisation, the results of the IRF's, show that the prices of the different forms of energy, respond mainly to their own shocks. However, equation (2) puts in evidence 
the existence of a relationship between the energy prices for the long run, indicating a small rate of adjustment of the market to price variations. The results support the possibility of substitution between natural gas and coal or heating oil prices, but present no evidence of substitution between coal and heating oil prices. It seems that external variables like income strongly influence the results, reducing the significance of the substitution effect among the energy types or even outperforming this effect.

In the residential sector, after liberalisation, the IRF's results maintain low statistical significance except for own shocks. Only two significant negative IRF responses were detected: the heating oil price response to coal price shocks and the natural gas price response to heating oil price shocks. The signs of the IRF's are in accordance with equations (3) and (4) confirming the apparent complementarity among these fuels. Once more the income variation, strongly affected by the petroleum prices, may be playing an important role on the negative inter-fuel relationships detected for the residential sector after liberalisation, in the long-run. These external factors seem to influence significantly the energy inter-price relationships, reducing the direct effect that a fuel price variation has on demand and on the prices of the other forms of energy.

As for the industrial sector, equation (5) indicates that in the long run fuel oil and coal or natural gas are substitutes. However, the low significance of the IRF's responses implies that the speed of adjustment of the industrial market is slow. These results are in accordance with Jones (1996) who showed that the strongest channels for the interfuel substitution in the UK industry are between natural gas and oil and between coal and oil, but suggested a slow response to price changes by the industrial energy users.

Positive significant IRF's responses of electricity price to coal and natural gas price shocks were detected for the industrial sector. Along with that, equation (5) points to a positive relationship among electricity and natural gas or coal prices. These positive relationships are mostly due to the fact that electricity is a secondary energy form generated in the UK mainly by the combustion of coal and natural gas. The development of daily markets trading electricity and natural gas may also contribute to the short run adjustment of the electricity to its cost of production, not possible in the presence of inflexible longerterm contracts.

The results for the industrial sector seem to be also strongly influenced by external variables, like income, which may be reducing the importance of the inter-fuel substitution effect or even hiding it. As in the residential sector, this contributes to the low significance of the results, specially the short-term ones, and also to the negative long run relationship detected between coal and natural gas prices. Also, the energy prices are linked closely to the international market, implying that the UK energy prices are largely determined by world prices and can only be partly explained by national variables.

As for the short term results, the use of multipart pricing, or "declining block pricing" (Clarkson and Miller, 1982, p 272) by most energy suppliers may also contribute to the negative responses detected in the short-run results. For example, a substitution of heating oil by natural gas by a consumer, will lead to an increase of the natural gas consumption allowing the consumer to have access to a more favourable rate, reducing the average price paid by him in the short term. Also, the market demand and its responsiveness to changes in prices is subject to technological constraints. As Fouquet et al (1997) pointed out, the costs of acquiring energy appliances are high and usually represent durable investments, which limits the interfuel substitution effect in the short-term. Thus, the energy market tends to present slow rates of adjustment, which contributes to the reduced significance of the results at the short horizon.

\section{CONCLUSIONS}

This paper explored the inter-relationship between the prices of different sources of energy in a liberalised market, based on VAR and cointegration techniques.

The IRF's results suggest low statistical significance both for the residential and industrial sectors. The prices of the different energy types respond mainly to their own shocks. It would be expectable to find an increased activity by the consumers after the liberalisation both for the residential and the industrial sectors. In fact, after the liberalisation of the natural gas and electricity markets the number of companies operating on these sectors largely increased in UK, revealing that the energy markets are becoming more competitive dropping the market shares of former monopoly companies. This will contribute to more flexible contracts and increasing market dynamism, which will be reflected on easier supplier switching. According to the European Commission estimations (Commission of the European Communities, 2002) 
the degree of costumer activity in terms of switching and renegotiating supplier in the UK was among the highest ones in the EU, both for the electricity and gas sectors, for the period 1998-2001. However, the models results do not allow drawing clear conclusions about the possibility of substitution and increased market dynamism after liberalisation.

In the long run, our results point to the existence of relationships among the energy prices, for the residential and industrial sector. This is in accordance with the results of Jones (1996) who also detected the possibility of adjustments of the energy markets on the long run. Or, as Bjprner and Jensen (2002) recently pointed out, in the longer perspective it is also captured the effect of new and closing companies, meaning that changes in energy demand may be related not only with substitution in the existing industrial companies, but also with the variations of the industrial structure. This way, variations on the relative energy prices will have an impact on the fuel choice for new energy consumers (industrial or residential).

The slow responsiveness of the energy markets can contribute to the difficulty on capturing and clarifying these relationships. The recent liberalisation of the market implied using a reduced amount of data to build the model for the residential sector after liberalisation, and to the use of mix data for the industrial sector, which also contributed to the small significance of the models.

It seems however that one of the major problems is the influence of external factors not captured by the models, which contribute to reduce or even hide the expected interfuel competition and substitution effects. In fact, the energy markets are strongly influenced and distorted by external factors like companies strategies, international markets movements, regulators interventions or oil related gas prices, meaning that only a small part of the energy price variations of each energy form can be associated with variations in its competitors prices. Among the explanatory variables of energy demand, aspects of the economic activity are normally used, like GDP or the income of the economic agents. Notwithstanding, it seemed quite challenging for us to analyse which could be the explanatory capacity of the energy prices over their own evolution in a liberalised environment, without using any other variable.

The inclusion of variables representing the economic activity should be the next step in this research. It is expected that this will contribute significantly to increase the general significance of the results and to clarify the signs of the interfuel relationships. Further studies should also address the industrial subsectors instead of using aggregated data, thus reducing the heterogeneity of each analysed group of consumers. As Bjprner and Jensen (2002) refer, the energy pattern is related to the industrial sub-sectors, reflecting differences in production technologies. Additionally, we think that the relationship between electricity price and coal and natural gas prices can be better assessed using data series of the coal and natural gas prices paid by electricity generators and relating it with the electricity prices paid by the industrial and residential consumers.

\section{ENDNOTES}

${ }^{1}$ An earlier version of this paper was presented at the IAEE Conference 2003 in Prague.

${ }^{2}$ A comparative survey of other interfuel studies for the industrial sector can be found in Jones (1996). For a survey of previous works see Pindyck (1979).

3 A detailed description of the UK reform of electricity and natural gas industries may be found in MacKerron (2003), Thomas (2003) and Thomas (1997).

${ }^{4}$ All price percentage changes presented in this section are based on tables of fuel price indices for the industrial and residential sector (Table 2.1.2 and 3.3.1) and of prices of fuels purchased by manufacturing industry (Table 3.1.3), drawn form Department of Trade and Industry (2003).

${ }^{5}$ All consumption shares presented in this section are based on the values of energy consumption by final user (Table DUKES 1.1.5, 2003) and the values of fuel input for electricity generation (Table DUKES 5.1, 2003), drawn form the Department of Trade and Industry site (www.dti.uk.gov).

${ }^{6}$ The remaining energy share is assigned to renewables, heat sold and other solid fuels.

${ }^{7}$ Tables 2.1.2 and 3.3.1 
${ }^{8}$ To support the robustness of the results the inverse order of the variables was tried for each model.

${ }^{9}$ The non-rejection of the null hypotheses for $\Delta$ o may result from the lag order used in the ADF tests. In fact, for this data series the AIC suggest the highest lag order value, among all the data series analysed.

9 The White's test (White, 1980) on the residuals indicated that the null hypotheses of no heteroscedasticity could not be rejected. The Ljung-Box Q-statistics (Ljung and Box, 1979) indicated no evidence of residual autocorrelation.

\section{REFERENCES}

Anari, A, Kolari, J, Pynnonen, S and Suvanto, A (2002) "Further evidence on the credit view: the case of Finland" Applied Economics 34 (3)267-278

Bj申rner, T and Jensen, H (2002) "Interfuel substitution within industrial companies: An analysis based on panel data at company level" The Energy Journal 23 (2) 27-50

Bussel, A (1997) “A VAR analysis of interest rates in Netherlands" Journal of Property Finance 8 (3) 246-263

Chang, T, Fang, W and Wen, L (2001) "Energy consumption, employment, output and temporal causality: evidence from Taiwan based on cointegration and error-correction modelling techniques" Applied Economic 33 (8)1045-1056

Clarkson, K and Miler, R (1982) Industrial organization. Theory, evidence and public policy”, McGraw Hill International Editions

Commission of the European Communities (2001) "First report on the implementation of the internal electricity and gas market” Commission Staff Working Paper, SEC(2001) 1957

Commission of the European Communities (2002) "Second report on the implementation of the internal electricity and gas market” Commission Staff Working Paper, SEC(2002) 1038

Department of Trade and Industry (2003a) “UK energy sector indicators 2003” (www.dti.gov.uk)

Department of Trade and Industry (2003b) “Quarterly energy prices- September 2003” (www.dti.gov.uk)

Department of Trade and Industry (2002) “Quarterly energy prices- December 2002” (www.dti.gov.uk)

Dickey, D and Fuller, W (1979) "Distribution of the estimators for autoregressive time series with a unit root " Journal of American Statistical Association 74 427-431

Dickey, D and Fuller, W (1981) "Likelihood ratio statistics for autoregressive time series with a unit root" Econometrica 49 (4) 1057-1072

Engle, R and Granger, C (1987) "Co-integration and error-correction representation, estimation and testing" Econometrica 55 (2) 251-276

Fouquet, R, Pearson, P, Hawdon, D, Robinson, C and Stevens, P (1997) "The future of UK final user energy demand” Energy Poilcy 25 (2) 231-240

Garcia-Cerruti, L (2000) "Estimating elasticities of residential energy demand from panel county using data dynamic random variables models with heteroskedastic and correlated error terms" Resource and Energy Economics 22 (4) 355-366

Haas, R and Schipper, L (1998), "Residential energy demand in OECD-countries and the role of irreversible efficiency improvements” Energy Economics 20 (4) 421-442 
International Energy Agency (2002) “The United Kingdom 2002 review” (www.iea.org)

Johasen, S (1991) "Estimation and hypothesis testing of cointegration vectors in Gaussian vector autoregressive models" Econometrica 59 (5)1551-1580

Jones, C (1995) “A dynamic analysis of interfuel substitution in US industrial energy demand” Journal of Business \& Economic Statistics 13 (4) 459-465

Jones, C (1996) "A pooled dynamic analysis of interfuel substitution in industrial energy demand by the G-7 countries" Applied Economics 28 (7) 815-821

Lin, W, Chen, Y, Chatov, R (1987) "The demand for natural gas, electricity and heating oil in the United States" Resources and Energy 9 233-258

Ljung, G and Box, G (1979) "On a measure of lack of fit in time series models" Biometrika 66 265-270

MacKerron, G (2003) "Electricity in England and Wales: efficiency and equity" in Glachant, J M and Dominique, F (ed) Competition in European electricity markets, Edward Elgar Publishing

Naka, A and Tufte, D (1997) "Examining impulse response functions in cointegrated systems" Applied Economics 29 (12) 1593-1603

OECD (2000), “OECD economic outlook”, No 67, June 2001

Ofgem (2001) "The new gas trading arrangement: further reform of the gas balancing regime” Feb. 2001 (www.ofgem.gov.uk)

Phillips, P and Perron, P (1988) "Testing for a unit root in time series regression" Biometrika 75 335-346

Pidyck, R and Rotemberg, J (1983) "Dynamic factor demands and effects of energy price shocks" The American Economic Review 73 (5) 1066-1079

Pidynk, R (1979) "Interfuel substitution and the industrial demand for energy: an international comparison" Review of Economics and Statistics 61 (2) 169-179

Renou-Maissant, P (1999) "Interfuel competition in the industrial sector of seven OECD countries" Energy Policy 27 (2) 99-110

Ryan, D, Wang, Y and Plourde, A (1996) "Asymmetric price responses of residential energy demand in Ontario" The Canadian Journal of Economics 29 (Special Issue) 317-323

Sims, C (1980) "Macroeconomics and reality" Econometrica, 48 (1) 1-47; in Chang et al (2001)

Thomas, S (2003) "Gas as a commodity. The UK gas market: From a nationalism to the embrace of a free market” in Arentsen, M and Kunneke, R (ed) National reforms in European gas, Elsevier

Thomas, S (1997) "The British market reform: a centralistic capitalist approach” in Midttun, A (ed) European electricity systems in transition, Elsevier

White, H (1980) "A heteroskedasticity-consistent covariance matrix and a direct test for heterokedasticity" Econometrica 48 (4) 817-838 